sane and insane males there was a loss of weight, there was, on the contrary, an increase in the females of both classes.

Of the three subdivisions of lung-disease, the cases of pulmonary phthisis were most numerous in the sane, amounting to 178 in the males and 97 in the females; also in the insane females to 80. In the insane males, pleuropneumonia was most frequent. The loss of weight in the cerebrum, as compared with the average in these cases of phthisis, was seven-tenths of an ounce in sane males, and there was an increase of one-tenth each in the cerebellum and pons; whilst in sane females the cerebrum was four-tenths of an ounce above, and the cerebellum, pons, and medulla, equal to the average. In the insane, the decrease in the cerebrum was eleven-tenths in the males, and sixtenths of an ounce in the females; and the cerebellum and pons in the males were one-tenth of an ounce below the average: in the females, the cerebellum and pons Varolii were of the average weight.

In disease of the heart, the encephalon attained the highest average weight in each sex and in both classes, being in males one ounce and three-quarters, and in females one ounce and a quarter above the average in the sane, the increase in weight being in all the parts. In the females it was confined to the cerebrum; in the insane males the in. crease in the cerebrum was four-tenths, and in the females one ounce and three-quarters; in the cerebellum, three-tenths in males; in the pons Varolii and medulla, one-tenth in females.

In the diseases of the abdominal organs in the sane males, the several parts of the encephalon were of the average weight; in the females the cerebrum was one and a half, and the cerebellum a quarter of an ounce above the average ; in the insane males the cerebrum was eight-tenths, and the pons one-tenth of an ounce above the average; and in the females the cerebrum was five-tenths, and the cerebellum one-tenth of of an ounce, above the average weight.

In fevers, the encephalon in the sane males was nine-tenths of an ounce, and in the females five-tenths of an ounce above the average; in the insane females the cerebrum was seven-tenths of an ounce above the average. There was but one male insane classed as a case of fever; the encephalon, unusually large, weighing fifty-five ounces and a half.

Of the diseases of the abdominal organs in the insane, including fevers, in females there were 133 cases; and the forms of mental disorder in the 47 males and $\$ 6$ females were in the following ratio per cent.

\begin{tabular}{|c|c|c|c|c|c|c|c|c|c|c|}
\hline \multirow{5}{*}{\multicolumn{3}{|c|}{$\begin{array}{l}\text { Mania } . .0 \\
\text { Melancholia } \ddot{~} \\
\text { Dementia and fatuity } \\
\text { General paralysis }\end{array}$}} & & & & & \multicolumn{2}{|c|}{ Males. } & \multicolumn{2}{|c|}{ Females. } \\
\hline & & & 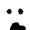 & 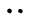 & $\cdots$ & $\bullet$ & 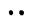 & $5 \mathrm{r} .2$ & (........... & 64.1 \\
\hline & & & & $\cdots$ & $\cdots$ & $\cdots$ & .. & 8.4 & n......... & 15.6 \\
\hline & & & & 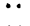 & 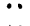 & $\ddot{*}$ & $\because$ & 29.8 & $\cdots \cdots \cdots$ & 17.2 \\
\hline & & .. & .. & .. & $\ddot{0}$ & $\ddot{0}$ & $\ddot{0}$ & $\frac{4.2}{-}$ & $\because \ldots \ldots$, & .2 \\
\hline & . & .. & . & .. & .. & .. & .. & 6.4 & .......... & 2.4 \\
\hline & & $\cdots$ & & - & - & - & .. & 100 & & 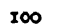 \\
\hline
\end{tabular}

In the whole number of insane-430 males and 351 females-the forms of mental disorder were in the following proportions per cent.

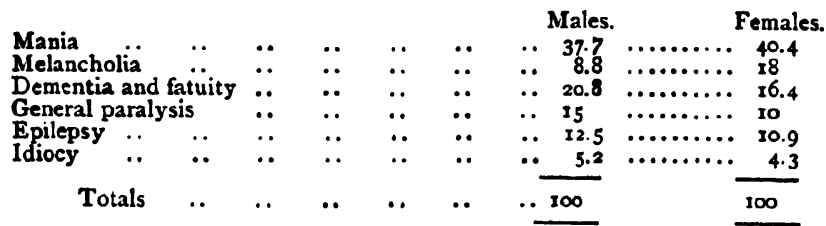

It may be observed, in conclusion, that the "assigned cause of death" was often difficult to determine in the insane, as it was frequently-in pulmonary disease, for example-associated with chronic inflammation of the cerebral membranes.

I. In diseases of the nervous system in the males, the numbers were 18 per cent. in the sane, and as many as 47 per cent. in the insane ; in the females of each class, the numbers were about 25 per cent., the cerebrum being below the average weight. The larger ratio in the insane males was due in great measure to the fatality of general paralysis in that class, which is usually accompanied by inflammation of the spinal cord. This statement was first published by me in 1848 , and subsequently confirmed by further examinations-some made by Dr. J. Ogle, at the Pathological Society of London.

2. The three pulmonary diseases, especially phthisis, were most frequent in sane males : in the sane and insane females the numbers were nearly equal. The weight of the cerebrum was in the males below, and in bronchitis and asthma, in females, above the average. In diseases of the vascular system, the brain was above the average, and the numbers in the sane were more than double the number in the insane.

3. The diseases of the abdominal organs were a third more in the insane than in the sane; and the brain was above the average weight, as it also was in fevers, which were most frequent in the sane, the in. sane being comparatively free.

From these observations on the different parts of the encephalon, it may almost be said that the variations in weight were confined to the cerebrum.

\section{NOTES ON THE CLIMATE OF ALGIERS.}

\section{BY WILLIAII THOMSOX, M.D., Resident English Physician, Algiers.}

AT this time of year, when many invalids in this country are beginning to ask themselves or their doctors where they ought to go to spend the winter months, I venture to bring forward the claims of Algiers as a health-resort of no small importance; and, in doing so, I have endeavoured to make my remarks as short and concise as possible, and to avoid all semblance of vaunting the comparative merits of the place : a practice which, I regret to say, is too common amongst some of my professional brethren. Having been in many climates, I have never as yet found, and never expect to find, a perfect one ; certainly Algiers is not; but I merely wish to describe it shortly as it is, and give a few short remarks from my own small experience as to the cases most suitable for sending there, in the hope that they may be of some small use to my fellow-practitioners at home, from many of whom I have received letters, asking for information regarding Algiers. My personal experience of Algiers and its climate only extends back as far as the last two winters; but the meteorological notes which I have made use of are taken from the published reports of M. Bulard, the director of the observatory at Algiers, who has laboured hard and conscientiously in making observations there during the last fourteen years, which observations can be far more implicitly relied on than stray ones made by casual residents.

The town of Algiers lies in 36.47 deg. N. latitude, and 3.4 deg. E. longitude, almost exactly five hundred miles S.S. IV. of Marseilles, with which town it has communication thrice weekly by the steamers of the Messageries Maritimes and Valery Companies, which do the passage in thirty-four hours. The town lies on a low range of hills called the Sahel, a prolongation of the Lesser Atlas mountains, which runs out to the sea here in the shape of a spur in a north-easterly direction, forming the western extremity of the Bay of Algiers, the breadth of which from here to its eastern extremity, Cape Matifon, is about sixteen miles. As the town and suburb of Mustapha, the favourite residence of the English visitors, lie on the south-east side of this range, they are thus protected from the north-west wind, the most prevalent one at Algiers, but which, from its passage across the sea, has no resemblance to the dry piercing mistral of the South of France. The form of the town is triangular, the base of the triangle being the French part of the town, and lying along the sea, whilst the cone comprises the old Arab quarters, and stretches up the hill, ending at the old fort or kasbah, the former residence of the Deys of Algiers. The town and suburb of Mustapha face the south-east, so that they enjoy a good exposure to the sun nearly all the day, whilst the view across the bay, with the fine range of the Djurjura Mountains in Kabylia, is of great beauty. The season for invalids may be said to be from the beginning of November to the end of April, though many English residents who are in the habit of staying on later say that May is the pleasantest month of all in Algiers. I should advise no invalids, however, to arrive there before November Ist, as the heat in October is sometimes still very trying. With that view, I should recommend all intending visitors to Algiers who leave England in the beginning of October (and I most decidedly think none, with few exceptions, suffering from pulmonary complaints should ever delay their departure later than the Ioth of that month) to cross over to Paris, where the temperature is usually warmer, and where the air, at any ratc, is free from the fogs to which London becomes liable about this time, and which are often so harmful; after spending a week or so in Paris, they can then move gradually southwards by stages, such as Dijon, Macon, Lyons, Avignon, Nismes, Arles, etc., to Marseilles, where they embark for Algiers. I would here offer another worl of advice on the subject of dress, and would most earnestly advise all, especially invalids, to take plenty of warm clothing with them, as, though the temperature of Algiers during the winter is, on an average, much the same as our summer in Eng. land, yet slight variations in it are much more felt than the same varia. tions at home.

The average mean temperature during the winter months in Algiers may be said to be $55.0 \mathrm{deg}$. Fahr.; the mean daily range between 10 deg. and 12 deg. Fahr. The mean height of the barometer at sea-level is $30.0 \mathrm{deg}$, and the daily variations are very slight, except 
during the occurrence of violent storms or on the approach of the sirocco.

The average rainfall during the winter season, i.e., from the beginning of November to the end of April, is abuut twenty-nine inches; the average number of rainy days about seventy. This may seem a very large quantity of rain and number of rainy days to many, but they must take into account the very different character of the rainfall from that of England. In Algiers, as a rule, the rain falls in tropical showers, lasting only an hour or two, instead of the slow drizzle to which we are accustomed at home. The months of November, December, and Janunry, as a rule, have the heaviest rainfalls. According to my own observations, the north-west wind is the most prevalent, and the south wind or sirocco fortunately the least prevalent of all the winds; it also, however, is quite different in character from the same wind felt in Malta or Italy, not containing the same moisture that it does there from crossing the sea, but being very dry and warm, and not so oppressive to breathe.

The climate of Algiers, especially that of the suburbs of Mustapha Supérieure and Bouzariah, where most of the English reside, is, on the whole, a tonic and bracing one. The soil is light, lying on a kind of tufa, which is very porous, so that the ground dries up very rapidly after rain, and one can walk out half an hour after the heaviest showers. There is abundant vegetation, and the gardens of the villas are rich in all varieties of flowers, which blossom all through the winter, whilst the orange and lemon-trees are most prolific. There are plenty of pleasant walks in the neighbourhood, which do not involve uphill exercise, while for riding or driving the roads are excellent and very varied.

I would here urge upon invalids in Algiers, as in other health-resorts, a fer simple precautions, which are too often neglected, either wilfully or through ignorance, which are, nevertheless, of vital importance for the preservation of health : for example, the strong necessity of avoiding being out of doors for an hour before and an hour after sunset. Many are in the habit of starting for long crives in open carriages and long walks on foot in the afternoon. Now, in winter in Algiers, the extreme temperature of the day is reached about I P.M., after which it begins to cool gradually, and, after 4 P.M., very rapidly, and there is a chilly feeling in the air, which continues till an hour after sunset, when the air, as a rule, becomes warm again, and very many of the nights at Algiers are extremely pleasant for going out in, with due caution in the case of invalids, especially in the town, where there is little or no dew-fall. With regard to diet also, which, in the hotels at any rate, is different in the style of cooking from that to which they have been accustomed at home, I would urge them to be careful in their selection from the very numerous forms of dishes placed before them. I have also seen much harm result from the evil habit of invalids with chest-complaints lunching, and more especially dining, in table athote rooms in hotels : tables d'hoti, as a rule, abroad are tediously prolonged entertainments, during which the room generally becomes like an oven, whence the invalid has to pass to his own room through icy passages or up countless flights of stairs. There may be exceptional cases where this is not so, but, in my experience, they are very exceptional.

At times in Algiers, especially when there is a south wind blowing, the dust is very trying, especially to those with pulmonary afiections; and, as a guard against this, I would advise the use of a veil or a respirator.

Speaking from my own experience, I should say that the climate of Algiers is of most undoubted value in those cases of phthisis where there is only as yet a slight deposit of tubercle in the lung or lungs, but that it does little more than prolong life for a time in those in whom the disease has gone the length of cavities; and it would be well if doctors at home thought twice before they sent out to Algiers or anywhere else some of the cases, in the most advanced stages, which it has been my misfortune to see there. In several cases in which, up to the time of their arrival, there had been excessive pyrexia, a marked fall in the temperature occurred, due, in a measure, I think, to the capital powers of sleeping which most arriving at Algiers enjoy, notwithstanding its proximity to the sea. In cases of old-standing fneumonia and pleurisy, I have seen much good done by a winter's residence at Algiers; but, in my opinion, those who, by some imprudence, contract maladies there, especially the low lobular forms of pneumonia, do not do so well, from what reason I do not profess to explain. All forms of bronchitis do remarkably well, especially the dry irritable variety and the chronic winter cough of the elderly. Every one of the numerous cases of asthma which I attended seemed to benefit by the climate, though, in this capricious disease, the improvement may have been purely accidental. The cases of emphysema I saw all did well, whilst most of the cardiac affections seemed to benefit from the mild equable temperature. I have heard that the climate of Algiers is not suitable for nervous complaints, and it may be so, as I have no opportunity of judging; but I see no reason why it should be so. All gastro-intestinal affections, amongst them three long-standing cases of Indian dysentery, did very well. I have only had two cases of typhoid fever in Algiers, and these came over in a yacht from Nice, and had the fever when they arrived. In the summer and autumn months, I believe there is a liability to typhoid and malarious fevers in the country around; but then it is precisely in these seasons that no one dreams of staying in or near Algiers. In the uterine cases which I attended, nearly every case seemed to benefit from the climate, and the menses became more regular in many long-standing cases of amenorrhcea; on the other hand, however, I have heard that the warm climate sometimes causes a too profuse discharge; but I can hardly fancy that it could do so in the winiter sea. son. It is impossible, however, to lay down general laws as to what class of cases will or will not suit the climate of Algiers, as nearly everything depends on the individual character of the complaint: a fact which $I$ think too many doctors at home are apt to ignore who appear to send cases at random to Mentone, Cannes, Algiers, etc., quite irrespective of the nature of the case or of the character of the climate. If these short remarks are of any service to any in deciding what to choose and what to avoid, they will not have been written in vain.

\section{SURGICAL MEMORANDA.}

\section{DISLOCATION OF THE PATELLA.}

As complete dislocation of the patella from direct mechanical violence is not of very frequent occurrence, the following case may be of interest. I was lately called upon to examine a gentleman who had met with a carriage-accident, in which he was thrown with great violence upon his left knee. I found him suffering from great pain in the knee, which was rigidly semiflexed, flattened in front, and broader than the other. The patella could be distinctly felt lying upon the outer side of the external condyle of the femur, its long axis being directed slightly outwards. Reduction was effected by straightening the knee and flexing the thigh upon the abdomen, combined with a little manipulation, so as to tilt the inner edge over the condyle.

\section{J. Johnston, M.B., Bolton.}

\section{OBSTETRIC MEMORANDA.}

\section{CASE OF TRIPLETS WITH A FOURTH BLIGHTED FEETUS.}

THE following case has lately occurred in my practice.

About 9 A.M. On the morning of August 25th, 1876, I was summoned to attend the wife of a coal-miner in the village of Brownhills. About an hour and a half after my arrival at the house, she was delivered of a full-grown male child, the presentation of which was breech. Twenty minutes or more after its expulsion, I made an examination, and found, on running my finger along the cord, a large rounded tense mass, which proved to be the membranes of another fotus. I waited for some time to see if the uterus would resume its action. After the expiration of two hours, I decided on rupturing the membranes, and, in twenty-five minutes afterwards, a second male child, considerably smaller than the first, was born. This presentation was pedal. Upon my placing my hand on the abdomen after this second birth, I found the uterus nearly as large as at first, and very little reduced in size. I made another examination, and found the membranes of a third fœtus presenting. These I speedily ruptured, and another fully developed male child (the largest of the three) was immediately born. This presentation was also breech. In about ten minutes after the expulsion of the third child, the patient had a strong labour-pain, and a foetus of presumably about three or four months was expelled.

There were two placenta; and, on examining them, I found that the cords of the second and third child, as well as that of the blighted foetus, were attached to one, and that of the first to the other placenta. The mother (who is about thirty-two years of age, and who has twice been delivered of twins) and the three infant male children, are doing well.

David Edgar FlinN, L.K.Q.C.P.I., Brownhills. 